\title{
Accidental Overdose of Oral Cyclosporine in Haematopoietic Stem Cell Transplantation: A Case Report and Literature Review
}

\author{
Ali Tafazoli ${ }^{1,2}$
}

Published online: 8 December 2015

(c) The Author(s) 2015. This article is published with open access at Springerlink.com

\begin{abstract}
A 26-year-old woman developed symptoms of acute toxicity during cyclosporine (CsA) therapy for graftversus-host disease prophylaxis. The standard regimen included CsA in a dose of $1.5 \mathrm{mg} / \mathrm{kg}(120 \mathrm{mg})$ every $12 \mathrm{~h}$, but, as a medication error, she received a high dose of $500 \mathrm{mg}$ of oral CsA. After $2 \mathrm{~h}$, she developed nausea and vomiting and, subsequently, flushing, chest tightness, tremor and vertigo. Laboratory and clinical examinations revealed high blood CsA concentrations $(1000 \mathrm{ng} / \mathrm{mL}$ after $12 \mathrm{~h}$ ) with a mild increase in blood pressure. Therefore, the patient was diagnosed with an acute CsA overdose. Before confirmation of the overdose by measurement of drug concentrations, the second dose was administered at its routine time because of uncertainty about the aetiology of the symptoms. The third dose was withheld, and the patient was monitored closely for clinical and laboratory presentations until the time when the abnormalities were relieved. CsA administration was then resumed with the correct prescription. The patient was discharged with successful engraftment and normal biochemical laboratory results after 1 month. Evaluation with the Naranjo assessment score indicated a probable relationship between the patient's symptoms and overdosage with the suspected drug. Currently, detailed presentations of acute CsA toxicity cases due to overdose are limited in the medical
\end{abstract}

Ali Tafazoli

tafazoli.m.a@gmail.com;

a.tafazzolimoghaddam@sbmu.ac.ir

1 Department of Clinical Pharmacy, Faculty of Pharmacy, Shahid Beheshti University of Medical Sciences, PO Box 14155/6153, Tehran, Iran

2 Taleghani Bone Marrow Transplantation Center, Taleghani Hospital, Shahid Beheshti University of Medical Sciences, PO Box 14155/6153, Tehran, Iran literature. Evaluation of the patient's medical and laboratory records, with cooperation of all responsible clinical staff, along with a review of the literature, were very helpful in discovery of the toxicity incident. Vigilance of health care providers with regard to medication errors and early detection of toxicity symptoms can decrease CsArelated morbidity and mortality in the future.

\section{Key Points}

The possibility of occurrence of cyclosporine toxicity should always be kept in mind in transplantation settings, because cyclosporine has a narrow therapeutic index, unpredictable pharmacokinetics and considerable probability of medication errors.

After administration of high-dose cyclosporine in the form of an oral formulation, infusion-reaction-like symptoms can occur. These symptoms are helpful in early detection of toxicity cases.

\section{Introduction}

Cyclosporine (CsA) is one of the most frequently used medications for immunosuppressive therapy to prevent graft-versus-host disease (GVHD), which is a life-threatening event for allogeneic haematopoietic stem cell recipients. The clinical response to CsA can be unpredictable, because of the complicated pharmacokinetics of CsA and the characteristics of the recipients [1]. 
Considering the widespread application of this drug, accidental overdoses and subsequent toxicities are highly probable, but, unfortunately, there are currently few case reports of acute CsA overdose in the literature, and only a small number of them have occurred in the setting of haematopoietic stem cell transplantation (HSCT). Patients undergoing HSCT generally have medical problems such as haematological malignancies or genetic immune disorders. In addition, co-medications used in HSCT are totally different from those used in solid organ transplantation or autoimmune disorders. Notably, the conditioning regimen in HSCT puts the patient at risk of a unique spectrum of CsA toxicities. Because of different underlying diseases, concurrent therapies and risk factors, the presentation of CsA toxicities in HSCT may be very different from those in other settings.

The aim of this report is to describe a patient with an iatrogenic CsA overdose in detail and the situation in which it happened. A literature review of similar cases, particularly in the setting of HSCT, has also been included in order to provide more awareness of early detection and management of such cases.

\section{Case Report}

A 26-year-old woman was admitted to an HSCT centre with acute myeloid leukaemia (AML). She weighed $79 \mathrm{~kg}$ and was $1.56 \mathrm{~m}$ tall (ideal body weight $48.8 \mathrm{~kg}$; body mass index $32.5 \mathrm{~kg} / \mathrm{m}^{2}$ ). She had a history of postpartum fever, fatigue, anaemia and high C-reactive protein (CRP) levels, and consequently received a diagnosis of AML with maturation (AML $\left.\mathrm{M}_{2}\right)$. After the first complete remission with a ' $7+3$ ' regimen, involving 7 days of cytarabine and 3 days of daunorubicin, with a full-match sibling donor, she became a candidate for allogeneic HSCT. The conditioning regimen consisted of busulfan from days -6 to -3 and cyclophosphamide on days -2 and -1 . GVHD prophylaxis included intravenous CsA $1.5 \mathrm{mg} / \mathrm{kg}$ every $12 \mathrm{~h}$ (120 mg per dose) from day -2 , and methotrexate $10 \mathrm{mg}$ on days $+1,+3,+6$ and +11 . An antibiotic prophylactic regimen comprised acyclovir, trimethoprim/sulfamethoxazole, fluconazole and ciprofloxacin, started on day -8 , all administered orally. The prescribed ciprofloxacin dosage was $500 \mathrm{mg}$ twice daily.

On day -3 , the patient mistakenly received $500 \mathrm{mg}$ of $\mathrm{CsA}$ as an oral soft gelatin capsule of a lipid micro-emulsion formulation, which was excessive, considering her ideal body weight. The patient had no mucositis nor gastrointestinal symptoms before that time. After about $2 \mathrm{~h}$, the patient experienced nausea and vomiting $(50 \mathrm{~mL})$. In the next $16 \mathrm{~h}$, the patient had nausea without another episode of vomiting, with reluctance regarding oral feeding, but had normal defaecation (no diarrhoea). The most annoying symptom described by the patient was a feeling of flushing and chest tightness from about $3 \mathrm{~h}$ after administration until the patient's bedtime ( $15 \mathrm{~h}$ later); then gradually it faded out and disappeared by the end of the first $24 \mathrm{~h}$, with initial sublingual temperature and respiratory rate elevations of about $0.5{ }^{\circ} \mathrm{C}$ and 5 breaths/min, respectively. The patient's (systolic/diastolic) blood pressure was around $115 / 85 \mathrm{mmHg}$ within $4-6 \mathrm{~h}$ of the overdosage, showing a mild increase from baseline $(105 / 70 \mathrm{mmHg})$, which was transient. Cardiac markers were normal. An electrocardiogram (ECG) was recorded for the patient at the start of the chest symptoms, repeated every $12 \mathrm{~h}$ and checked by a cardiologist, with no detectable pathological alterations (not even tachycardia). The third noticeable complaint was dizziness, which was remembered by the patient after the vomiting and occurred with the same pattern as the flushing. On clinical neurological examination, the only findings were a transient mild upper limb tremor and benign paroxysmal positional vertigo. Other findings, including deep tendon reflexes, plantar reflexes, and other sensorymotor and cranial nerve examinations, were normal.

A complete blood cell count and biochemistry profile were requested for the patient from the time of the start of symptoms and after $9 \mathrm{~h}$, then as a $12 \mathrm{~h}$ routine schedule. Some markers, such as CRP, were monitored at longer intervals, as per our centre's policies. The patient's laboratory test values are summarized in Table 1 . Because none of the laboratory results explained the symptoms (they were generally normal values for the patient), a clinical pharmacy consultation was requested for possible drugrelated complications after $6 \mathrm{~h}$ post-administration.

After a thorough interview with the patient and the responsible nursing staff who had observed her continuously during this period, and after investigation of her medical record and medication chart, it was found that the ciprofloxacin prescription was hardly readable, and the most probable drug name mistakenly substituted for 'ciprofloxacin' was 'cyclosporine'. After $12 \mathrm{~h}$ post-administration, a whole-blood sample for measurement of the CsA concentration was sent for evaluation of hypothetical trough concentrations. The next morning was day -2 pretransplantation, so, despite a recommendation from the clinical pharmacy service for a CsA stop order until the CsA concentration results became available (the turnaround time is about $12-24 \mathrm{~h}$ at our centre), $120 \mathrm{mg}$ of intravenous CsA was administered as per the routine GVHD prophylaxis schedule because of uncertainty about the extent of exposure and the low probability of a medication error; however, another blood sample was sent for drug concentration measurement just prior to its administration. After $4 \mathrm{~h}$, the result for the first sample was reported as $1000 \mathrm{ng} / \mathrm{mL}(12 \mathrm{~h}$ post-dose $)$. The second 
Table 1 Timetable of clinical events in relation to the first and second cyclosporine (CsA) exposures

\begin{tabular}{|c|c|c|c|c|c|c|c|c|c|c|}
\hline \multirow{3}{*}{$\begin{array}{l}\text { Parameter } \\
\text { Time post- } \\
\text { administration of } \\
\text { CsA }\end{array}$} & \multicolumn{9}{|c|}{ CsA exposures } & \multirow{3}{*}{$\begin{array}{l}\text { Resumption } \\
\text { of routine } \\
\text { GVHD } \\
\text { prophylaxis } \\
48 \text { h: day - } \\
1 \text { pre-Tx }\end{array}$} \\
\hline & \multicolumn{7}{|c|}{ First exposure (oral dosing, medication error) } & \multicolumn{2}{|c|}{$\begin{array}{l}\text { Second exposure } \\
\text { (intravenous dosing, } \\
\text { scheduled administration) }\end{array}$} & \\
\hline & $\begin{array}{l}0 \mathrm{~h}: \\
\text { day } \\
-3 \\
\text { pre- } \\
\text { Tx }\end{array}$ & $2 \mathrm{~h}$ & $3 \mathrm{~h}$ & $4 \mathrm{~h}$ & $6 \mathrm{~h}$ & $12 \mathrm{~h}$ & $18 \mathrm{~h}$ & $\begin{array}{l}24 \mathrm{~h} \text { : day }-2 \\
\text { pre-Tx }\end{array}$ & $36 \mathrm{~h}$ & \\
\hline \multicolumn{11}{|l|}{ Vital signs } \\
\hline $\mathrm{T}\left({ }^{\circ} \mathrm{C}\right)$ & 37 & & 37.5 & 37.5 & 37.2 & 37.3 & 37.2 & 37 & 37 & 37 \\
\hline PR (beats/min) & 69 & & 72 & 72 & 69 & 69 & 69 & 69 & 69 & 69 \\
\hline RR (breaths/min) & 14 & & 19 & 15 & 14 & 14 & 14 & 14 & 14 & 14 \\
\hline $\begin{array}{l}\mathrm{BP}(\mathrm{mmHg} ; \\
\text { systolic/diastolic) }\end{array}$ & $\begin{array}{r}105 / \\
70\end{array}$ & & - & $\begin{array}{r}115 / \\
90\end{array}$ & $115 / 80$ & $115 / 80$ & $115 / 80$ & $115 / 80$ & $110 / 70$ & $105 / 70$ \\
\hline $\begin{array}{l}\text { Relevant } \\
\text { observations }\end{array}$ & - & $\begin{array}{l}\mathrm{N}, \\
\mathrm{V}, \\
\mathrm{Di}\end{array}$ & $\begin{array}{l}\text { N, Di, Ch, F, } \\
\text { normal } \\
\text { ECG, } \\
\text { normal } \\
\text { CardEnz, } \\
\text { normal } \\
\text { ABG }\end{array}$ & $\begin{array}{l}\text { N, Di, } \\
\text { Ch, } \\
\text { F }\end{array}$ & $\begin{array}{l}\mathrm{N}, \mathrm{Di}, \mathrm{Ch}, \mathrm{F}, \\
\text { neuro } \\
\text { examination }\end{array}$ & $\begin{array}{l}\text { N, Di, Ch, F, } \\
\text { normal } \\
\text { ECG, } \\
\text { normal } \\
\text { CardEnz, } \\
\text { normal } \\
\text { ABG }\end{array}$ & $\begin{array}{r}\text { Patient } \\
\text { slept }\end{array}$ & $\begin{array}{l}\text { Resolution } \\
\text { of } \\
\text { symptoms, } \\
\text { normal } \\
\text { ECG }\end{array}$ & $\begin{array}{l}1 \text { dose } \\
\text { withheld }\end{array}$ & - \\
\hline \multicolumn{11}{|c|}{ Laboratory test values $^{\mathrm{a}}$} \\
\hline $\begin{array}{l}\text { WBCC }\left(10^{3} / \mu \mathrm{L}\right) \\
{[3.5-10.5]}\end{array}$ & 8.7 & & 8.3 & & & 7.5 & & 8 & 8.7 & 9.6 \\
\hline $\begin{array}{l}\operatorname{RBCC}\left(10^{3} / \mu \mathrm{L}\right) \\
{[3.9-5.7]}\end{array}$ & 4.72 & & 4.6 & & & 4.65 & & 4.78 & 4.7 & 4.2 \\
\hline BS (mg/dL) & 86 & & 102 & & & 145 & & 200 & 162 & 141 \\
\hline $\begin{array}{l}\mathrm{Na}(\mathrm{meq} / \mathrm{L}) \\
{[135-145]}\end{array}$ & 140 & & 141 & & & 139 & & 141 & 136 & 149 \\
\hline $\begin{array}{l}\mathrm{K}(\mathrm{meq} / \mathrm{L}) \\
{[3.5-5]}\end{array}$ & 4.2 & & 4.1 & & & 4.2 & & 4.8 & 4.8 & 4.2 \\
\hline $\begin{array}{l}\mathrm{Ca}(\mathrm{mg} / \mathrm{dL}) \\
{[8.5-10.5]}\end{array}$ & 9.8 & & - & & & 9.5 & & 9.6 & 8.8 & 8.5 \\
\hline $\begin{array}{l}\mathrm{Cr}(\mathrm{mg} / \mathrm{dL}) \\
{[0.5-1.3]}\end{array}$ & 0.7 & & 0.7 & & & 0.7 & & 0.7 & 0.7 & 0.7 \\
\hline $\begin{array}{l}\mathrm{CRP}(\mathrm{mg} / \mathrm{L}) \\
{[<10]}\end{array}$ & 1.5 & & - & & & - & & 1.5 & - & 1.5 \\
\hline $\begin{array}{l}\text { ALT (IU/L) } \\
{[<40]}\end{array}$ & 24 & & 22 & & & 26 & & 25 & 28 & 21 \\
\hline $\begin{array}{l}\text { Bili-T (mg/dL) } \\
{[0.3-2]}\end{array}$ & 0.3 & & 0.4 & & & 0.4 & & 0.4 & 0.3 & 0.5 \\
\hline $\begin{array}{l}\text { Drug conc }(\mathrm{ng} / \\
\mathrm{mL})[100-300]\end{array}$ & & & & & & 1000 & & 600 & 410 & 276 \\
\hline
\end{tabular}

$A B G$ arterial blood gases, $A L T$ alanine aminotransferase, Bili-T total bilirubin, $B P$ blood pressure, $B S$ blood sugar, $C a$ calcium, $C a r d E n z$ cardiac enzymes, $C h$ chest tightness, conc concentration, $C r$ serum creatinine, $C R P$ C-reactive protein, Di dizziness, ECG electrocardiogram, $F$ flushing, $G V H D$ graft-versus-host disease, $K$ potassium, $N$ nausea, $N a$ sodium, neuro neurological, $P R$ pulse rate, pre- $T x$ pre-transplantation, $R B C C$ red blood cell count, $R R$ respiratory rate, $T$ temperature, $V$ vomiting, $W B C C$ white blood cell count

a The values listed in [square brackets] are the normal ranges

sample showed a $600 \mathrm{ng} / \mathrm{mL}$ CsA concentration at $24 \mathrm{~h}$ after administration of the mistaken dose. Consequently, another drug concentration measurement was requested $12 \mathrm{~h}$ after the first intravenous dose, and the next dose was withheld. The patient had no flare of symptoms after administration of the first intravenous dose. After 12 and $24 \mathrm{~h}$ of intravenous dosing, the drug concentrations were 410 and $276 \mathrm{ng} / \mathrm{mL}$, respectively, and the patient was 
symptom free; therefore, routine administration of CsA $120 \mathrm{mg}$ every $12 \mathrm{~h}$ was resumed. Afterwards, during the admission, CsA trough concentrations were checked twice weekly and, on all occasions, the values were between 200 and $400 \mathrm{ng} / \mathrm{mL}$ without any dose modification, except for one subtherapeutic concentration.

We had the chance to calculate the area under the blood concentration-time curve (AUC) of CsA and the consequent pharmacokinetic profile of CsA for this patient after 5 days of transition to the oral dosage form on posttransplantation day +18 (but unfortunately not during the intoxication phase). With $250 \mathrm{mg}$ dosing, the AUC, peak concentration $\left(C_{\max }\right)$, time to reach $C_{\max }\left(t_{\max }\right)$, clearance, bioavailability and half-life were $3777.5 \mathrm{ng} \cdot \mathrm{h} / \mathrm{mL}, 800 \mathrm{ng} /$ $\mathrm{mL}, 2 \mathrm{~h}, 22.5 \mathrm{~L} / \mathrm{h}, 34 \%$ and $3.85 \mathrm{~h}$, respectively.

The patient was discharged with successful engraftment and normal biochemical laboratory results on day +31 . On follow-up assessments, she was diagnosed with Glucksberg grade IV acute GVHD on day +43 , which resulted in readmission. It was treated successfully with antithymocyte globulin, methylprednisolone and mycophenolate mofetil.

\section{Methods}

To find detailed information about presentations of patients with CsA overdose in the literature, two accredited scientific databases, PubMed and ScienceDirect, were explored. Searching PubMed with a ('cyclosporine'[Majr]) AND 'toxicity'[Subheading] or 'drug overdose'[Majr:NoExp] command, and filtering the results by 'case reports', yielded only 11 and 5 journal articles, respectively. In addition, the Medical Subject Heading (MeSH) terms 'cyclosporine' and 'medication errors' were applied to obtain more data on this issue, but only one article was found. To avoid overlooking other relevant data, the author also tried using a ('Cyclosporine/adverse effects' [Majr] OR 'Cyclosporine/ poisoning' [Majr] OR 'Cyclosporine/toxicity'[Majr]) AND 'Hematopoietic Stem Cell Transplantation'[Majr] search command, which identified 24 journal articles. The ScienceDirect database was also explored in the 'advanced search' mode with a TITLE-ABSTR-KEY(cyclosporine) and TITLE-ABSTR-KEY(toxicity) command, which yielded 925 outputs after 1983-the year in which CsA received approval from the US Food and Drug Administration for use in transplantation. A similar search process using the terms 'cyclosporine' and 'overdose' resulted in 855 journal articles. After screening, it was determined that most of these articles were irrelevant to the scope of this report. From them, the author chose only 15 cases, on the basis of their relevance, to build this review on CsA overdose. Also, some other useful articles were added to provide further explanation about the reports.

\section{Results and Discussion}

The 26-year-old female allogeneic HSCT recipient presented here mistakenly received a high CsA dose of $500 \mathrm{mg}$ on day -3 , instead of a $120 \mathrm{mg}$ intravenous dose, because the medication prescription was hardly readable and it was mistaken for another commonly used peritransplantation drug with a similar name. This overdosage caused signs and symptoms of acute adverse reactions and toxicity. To our knowledge, the demonstrated constellation of symptoms, as we observed collectively in this case and in this specific setting, seems to be unique in the medical literature.

\section{Symptoms}

It has been stated frequently that signs and symptoms of CsA acute adverse reactions or toxicities can present both with therapeutic doses and with overdoses. However, the probabilities of some reactions, such as neurotoxicity or nephrotoxicity, are higher with higher CsA doses and blood concentrations [1]. As mentioned, our patient's symptoms generally were of a gastrointestinal, cardiovascular and neurological nature. Gastrointestinal intolerance has been identified as one of the most important CsA side effects, which is preventable by a 'go low, go slow' strategycontrary to what happened to our patient [2]. Such complications are commonly reported with oral CsA overdose and are highly predictable with the first dose-and this was the first complaint of our patient as well. Sensations of increased abdominal girth, taste disturbance, anorexia and mild stomach upset were reported in a multiple sclerosis case after unintentional overdosing of oral CsA for 8 days. After discontinuation, the stomach upset was relieved within a day, but it took 2 weeks for the anorexia and the sensation of increased abdominal girth [3] to disappear.

Gastroparesis accompanied by nausea, vomiting, bloating and early satiety have been associated with CsA administration in bone marrow transplant patients [4]. In our patient, the onset of the gastrointestinal adverse reaction was consistent with the timing of the estimated $C_{\max }$ values in the pharmacokinetic evaluations.

According to our search results, nephrotoxicity is one of the most frequently reported toxicities of CsA even in acute circumstances. Besides numerous other aetiologies, CsA has been implicated as the main cause of renal failure after HSCT [5]. It has been shown that such damage can be either reversible or irreversible. Acute kidney injury (creatinine levels increased from 1.1 to $1.4 \mathrm{mg} / \mathrm{dL}$ ) has been reported with a CsA overdose, which was corrected about 1 day after withdrawal [3]. Conversely, in a 29-year-old lung transplant recipient who received a $30 \mathrm{mg} / \mathrm{kg} / \mathrm{day}$ dose instead of $3 \mathrm{mg} / \mathrm{kg} /$ day by mistake, progressive anuria 
and a subicteric status presented with blood CsA concentrations of $4100 \mathrm{ng} / \mathrm{mL}$ after $18 \mathrm{~h}$. CsA was stopped but then resumed after 4 days with detection of $80 \mathrm{ng} / \mathrm{mL}$ blood concentrations. After 10 days, the icterus had disappeared, but renal failure with proteinuria necessitated continued use of haemodialysis for 6 weeks post-transplantation. The patient's final creatinine clearance measurement was $18 \mathrm{~mL} / \mathrm{min}$, without further improvement, and he died of endocarditis-septic shock after 14 weeks [6]. Generally, it could be stated that dose dependency, or pharmacokinetic allowable of this adversity, is not a constant finding [7, 8]. In our case, an episode of an increase in serum creatinine was observed around day +15 , but this was after several days of administration of an aminoglycoside (amikacin) for a new-onset fever. This makes CsA overdose a less relevant aetiology. Serum creatinine levels are routinely measured for this adverse effect at our centre, as at other centres, but it should be kept in mind that the possibility of a temporal delay between an initial CsA insult and the onset of biochemically detectable renal impairment has been proposed in the literature [9].

Neurotoxicity could be the most prominent acute symptom observed with CsA overdose [10]. CsA neurotoxicity is an annoying-but common-complication in HSCT, with a wide spectrum of presentations ranging from tremors, restlessness, dysesthesias of the palms and soles, paraesthesia, headache, depression, confusion and somnolence to Parkinsonism, seizures, altered mental status with confusion, visual or auditory hallucinations, cortical blindness, encephalopathy, and coma. Specifically, symptoms such as a burning sensation in the mouth, plus feet and hand hyperaesthesia, have been reported with CsA overdose, and disappeared 1 week after withdrawal [3].

In the first published case report of a fatal CsA overdose in an adult, a 51-year-old man with a lung transplant received a $30 \mathrm{mg} / \mathrm{h} \mathrm{CsA}$ infusion (instead of $3 \mathrm{mg} / \mathrm{h}$ ) for $13 \mathrm{~h}$; this resulted in massive cerebral oedema and death. The first symptoms were bilateral, reactive mydriasis and absence of cutaneous and tendinous reflexes. Diffuse cerebral oedema was detected by computed tomography. Then, through development of severe intracranial hypertension, progressive, non-reactive, bilateral mydriasis and disappearance of cephalic reflexes also occurred, which ended in the patient's death. An important finding of this report was that the $\mathrm{CsA}$ concentration after $7 \mathrm{~h}$ of the toxic infusion was $1256 \mathrm{ng} / \mathrm{mL}$ despite recordings of therapeutic concentrations in routine daily measures, because of missing $C_{\max }$ measurements. Just like our patient, this patient had serum creatinine and hepatic enzyme levels within normal ranges [11].

In the setting of HSCT, a 34-year-old woman with myelodysplastic syndrome was described as having a severe occipital headache immediately after transplantation, development of acute-onset left-sided weakness, blurred vision in the right eye, confusion, incomprehensible speech and seizure activity on the left side of the body on day +5 , which was related to CsA neurotoxicity concurrent with therapeutic concentrations (279 ng/mL) [12]. Acute (early-onset) posterior encephalopathy has also been reported $36 \mathrm{~h}$ after initiation of CsA infusion for GVHD prophylaxis. The symptoms, which included a seizure, headache, visual disturbances and altered mental status, were reversible after CsA withdrawal [13]. Although these two instances occurred at therapeutic doses and therapeutic blood concentrations, they were concomitant with the start and increased concentrations of CsA.

Tremor is one of the most alarming and easily detectable symptoms of CsA toxicity. This presentation is referred to as 'toxic transplant tremor'. It generally arises from severely elevated blood drug concentrations [14]. The occurrence of a synergistic and deteriorating effect has also been proposed when CsA is co-administered with other neurotoxic drugs [15], which is a prevalent occasion in HSCT conditioning. Our patient had significant neurological complications, including tremor and vertigo. Considering the time proximity of the overdosage and symptoms, it could be stated that there was a high probability that the patient presentation's was caused by CsA. The Naranjo assessment score was 6 , as there have been previous conclusive reports on the reaction $(+1$ point $)$; the adverse event occurred just after the drug administration (+2 points); the adverse reaction was improved by withholding a dose and decreasing blood concentrations (+1 point); the same administration did not reoccur for the patient ( 0 points); there were alternative possible causes, such as the conditioning regimen, for the reaction (1 point); no placebo was given for checking (0 points); high blood concentrations were detected ( +1 point); the reaction was undetectable when the dose was decreased $(+1)$; it was the first exposure for the patient ( 0 point); and the adverse event was confirmed by objective laboratory and clinical examinations (+1 point). If possible, neuroimaging studies should be implemented in such instances, but, because of the subtle clinical picture with rapid resolution, a clinical decision was made not to break the patient's microbial isolation. In many similar observations, a neurotoxic syndrome has been detected at therapeutic blood CsA concentrations. Therefore, the presence of a complicated drug-effect correlation, and a possible role of numerous intruding factors of the patient's peri-transplantation status, could be proposed.

CsA can induce a range of cardiovascular effects, from mild complications to life-threatening adverse effects. Low-level hypertension is a common finding in CsA recipients. The occurrence of a transient increase in blood 
pressure through complex mechanisms soon after administration of CsA has been suggested [16]. Even the coronary and cerebral vascular systems are affected by this medication, which can result in hazardous outcomes. Also, direct cardiotoxic effects have been reported with CsA, such as sinus bradycardia [17] or decreased myocardial contractile force [18]. In a report of a 61-year-old candidate for kidney transplantation, inadvertent preoperative administration of CsA $1000 \mathrm{mg}$ instead of mycophenolate caused atrial fibrillation. Besides heart rhythm problems, the patient showed no other abnormality on clinical and laboratory examinations. Serum CsA concentrations at 1 and $18 \mathrm{~h}$ after ingestion were 2438 and $123 \mathrm{ng} / \mathrm{mL}$, respectively. The ECG was normalized to sinus rhythm within $1 \mathrm{~h}$. After $24 \mathrm{~h}$, the patient was asymptomatic and was discharged [19]. Peripheral symptoms such as flushing of the face and foot swelling have also been reported with CsA overdose [3].

Interestingly, our patient demonstrated an infusion-reaction-like syndrome, including flushing and chest tightness with the solid oral product. This could be explained by acute release of a relatively large amount of the drug into the bloodstream in the first CsA exposure. Despite previous observations of similar reactions to intravenous CsA [20], our report proposes that 'first' and 'high' exposure would also be considerable factors for such complications, besides the dosage form. At our centre, blood pressure is measured every $6 \mathrm{~h}$ in all transplant patients, and on seven consecutive occasions (at 4, 6, 12, 18, 24, 30 and $36 \mathrm{~h}$ after dosing), the patient's blood pressure was higher than at baseline although this required no therapy, but such a rapid effect on the cardiovascular system was considerable (and this finding was inconsistent with an anaphylactoid reaction). According to the above-mentioned studies, performance of an ECG and cardiac enzyme monitoring (due to the chest symptoms of the patient) were rational and recommendable approaches in such circumstances.

\section{Management}

It could be stated that currently there is no globally accredited guideline for management of CsA overdose especially in the setting of HSCT, but gathering the sparse data available from several case reports would be helpful in achieving a consensus.

In one of the foremost reports of CsA overdose, a 32-year-old kidney transplant recipient received CsA $5000 \mathrm{mg}$ instead of $750 \mathrm{mg}$. The medication error was discovered $3 \mathrm{~h}$ after ingestion. For management of the situation, practitioners administered activated charcoal $60 \mathrm{~g}$ followed by two $30 \mathrm{~g}$ doses every $4 \mathrm{~h}$, with two doses of magnesium citrate between the charcoal doses. The plasma drug concentrations were 6700, 675 and $50 \mathrm{ng} / \mathrm{mL}$ at 4, 13 and $47 \mathrm{~h}$ after ingestion, respectively. The authors calculated the CsA apparent half-lives as being much shorter during charcoal administration [21].

Among the paediatric population, acute overdose with $30 \mathrm{~mL}$ (300 mg or $170 \mathrm{mg} / \mathrm{kg}$ ) of a CsA liquid formulation has been reported in a 4.5 -year-old, $17 \mathrm{~kg}$ renal transplant recipient. Gastric decontamination was undertaken with ipecac syrup $1 \mathrm{~mL} / \mathrm{kg} 20 \mathrm{~min}$ after ingestion, which was ineffective, and this was repeated $40 \mathrm{~min}$ after ingestion, with successful emesis. One hour after ingestion, activated charcoal $2 \mathrm{~g} / \mathrm{kg}$ plus sorbitol was administered in the emergency department. Measurement of blood CsA concentrations after $2 \mathrm{~h}$ showed therapeutic concentrations. After $4 \mathrm{~h}$, the patient was stable without an intoxicated appearance, so he was discharged and, on medical instructions, only his next CsA dose was skipped [22].

Besides gastrointestinal decontamination, enhancement of metabolic elimination with pharmacological enzyme inducers, such as rifampin, phenytoin or phenobarbital, has been tried with partial success in some instances [23]. In a 61-year-old man, after administration of $75 \mathrm{~mL}$ of CsA emulsion (7500 $\mathrm{mg}$ ) via a feeding tube in hospital, the CsA trough concentration was $3687 \mathrm{ng} / \mathrm{mL}$. When intravenous phenytoin was started for management of central nervous system symptoms, the CsA trough concentration decreased to $171 \mathrm{ng} / \mathrm{mL}$ after about 5 days [10].

Also, a 68-year-old man with a transplanted kidney received a 100-fold oral overdose of $\mathrm{CsA}$, which was discovered within $2 \mathrm{~h}$. Measurements showed plasma CsA concentrations over $1500 \mathrm{ng} / \mathrm{mL}$. Detoxification therapy started with intensive gastric lavage followed by suction and instillation of cholestyramine $(4000 \mathrm{mg} / \mathrm{bag})$ but after $8 \mathrm{~h}$, the concentrations were only slightly decreased. Considering CsA pharmacokinetics and distributive characteristics, whole-blood exchange (WBE) was performed. For management of CsA-related acute renal failure, continuous haemofiltration was applied $2 \mathrm{~h}$ after WBE. No considerable change in serum CsA concentrations was found after WBE. However, plasma CsA concentrations were rapidly decreased after haemofiltration was started, falling to $802 \mathrm{ng} / \mathrm{mL}$ after $2 \mathrm{~h}$ and to $159 \mathrm{ng} / \mathrm{mL}$ after $72 \mathrm{~h}$ of continued haemofiltration, respectively. After 5 days of haemofiltration for anuria, the patient recovered and was finally discharged. On the basis of pharmacokinetic calculations, the authors raised doubt that the CsA elimination during haemofiltration could also have been a consequence of its original elimination rate; therefore, they suggested hemofiltration only for patients with fully formed renal impairment [24].

A 55-year-old cardiac transplant patient received a 50-fold oral overdose of CsA ( $35 \mathrm{~mL}$ instead of $0.7 \mathrm{~mL}$ ), which was mistakenly administered via an L-tube after the medication prescription was changed from a solid oral 
form to a syrup dosage form. Only transient deterioration of renal and hepatic function was noted. Because of the delay in detection, without gastrointestinal decontamination, the patient was treated with WBE by the apheresis method. The blood concentration decreased from $8900 \mathrm{ng} /$ $\mathrm{mL}$ to $285.7 \mathrm{ng} / \mathrm{mL}$ after 3 days of the process, with normal serum creatinine and bilirubin levels [25].

Since our major focus is on HSCT patients, our review of the literature includes a report in which a 38-year-old female allogeneic transplant recipient, after an intensive care unit admission and recovery, was prescribed a CsA oral suspension in a dosage of $125 \mathrm{mg}$ twice daily via a nasogastric tube. However, the patient received an inadvertent overdose of $5000 \mathrm{mg}$ on the first administration. The CsA overdose was discovered about $6.5 \mathrm{~h}$ after ingestion, and a blood concentration of $1797 \mathrm{ng} / \mathrm{mL}$ was recorded. After lavage, $50 \mathrm{~g}$ of activated charcoal and acetylcysteine were administered about 7.5 and $8 \mathrm{~h}$ after the CsA dose, respectively. Presentation of seizure-like activities was managed with phenobarbital. Serial magnetic resonance imaging (MRI) was performed for detection of posterior reversible encephalopathy syndrome. To help reduce the patient's CsA concentrations, both plasma exchange and red blood cell (RBC) exchange were performed sequentially. In contrast to the previous report, at first the plasma exchange was initiated to avoid a delay in procurement of red cells. The CsA concentration was $782 \mathrm{ng} / \mathrm{mL}$ at the end of the plasma exchange, which was remarkable. After RBC exchange, the CsA concentration was reduced to $691 \mathrm{ng} / \mathrm{mL}$. Another plasma exchange was also performed about $23 \mathrm{~h}$ after the overdose, after which the patient's CsA concentration had reached the upper limit of the normal therapeutic range. Over the next week, the patient's condition stabilized, and MRI showed clearance of mild white matter changes [26].

As we can see in these chronologically ordered case reports, therapeutic approaches have evolved a little from the earlier reports, yet it seems that a straightforward treatment method with proven efficacy has not been achieved.

\section{Medication Errors}

Acute CsA overdose has been reported more frequently with oral formulations but more severely with parenteral administration [27], and this may imply a lack of adequate outpatient education, besides more frequent use of oral formulations. In a report from the Swiss Toxicological Information Centre, iatrogenic errors were incriminated in about $46 \%$ of overdose cases [28]. As stated in the abovementioned case reports, acute CsA intoxication due to overdoses at medical centres can originate from 'prescribing errors' such as illegible handwriting, 'medication errors' including administration of the wrong doses due to peri-transplantation poly-pharmacy, misreading of decimals or zeros, miscalculation of the dose from one formulation to another and, finally, 'negligence' of the involved staff, making errors such as transcription errors in wards and pharmacies. A major challenge in such fields is medication error in substitution of solid oral formulations with liquid formulations [29]. Different amounts of drug per dose, different bioavailability, and different units of measurement may cause confusion, especially for administrators with less experience. In our case, a misreading of the ciprofloxacin prescription, resulting in erroneous administration of a 'ciprofloxacin-sized' dose of CsA, resulted in the overdose event. This fact underscores the roles of poly-pharmacy, prescribing error and medication errors in overdose cases. It should also be noted that the drug name 'cyclosporine' has different variants, including 'ciclosporin', which augments the potential for error through the similarity of this name to the drug name 'ciprofloxacin'.

\section{Conclusion}

Widespread use of CsA in the transplantation setting potentially has resulted in numerous cases of overdose and intoxication, but the number of reports in the medical literature is very small. In HSCT, the role of correct CsA dosing is very prominent because of the very high mortality rate associated with GVHD, the weakened state of patients after conditioning chemo-radiation without a successful transplant, and lack of suitable alternative therapeutic options. Therefore, both prevention and management of CsA overdose in HSCT are of great importance. These patients have different underlying diseases, co-medications, risk factors for toxicity and pharmacokinetic profiles for CsA, so different presentations of CsA overdose may occur in the HSCT population.

For prevention of such instances, use of typewritten prescriptions and labels, double-checking and use of more experienced staff for administration of peri-transplantation medications are highly recommended. Also, use of educational pamphlets or training classes on 'drug name similarities' would be helpful. At our centre, we have instituted a new policy that every physician's prescription should be double-checked by two nurses (one of them should be the shift head nurse) before administration. Also, emergency contact with the physician about any suspicious handwriting is now obligatory for every drug-administering nurse.

For treatment, according to the above-mentioned reports, drug withdrawal and gastrointestinal decontamination are the first steps and seem to be the most effective 
strategy for management of CsA overdose. In light of this fact, early detection of the overdose is very important. Therefore, knowledge of the major and distinctive signs and symptoms of acute CsA intoxication in each specific population is very useful, and this is the main goal of this report. In our review of the relevant literature, common presentations of CsA intoxication have been summarized, but, because of the scarcity of data in the setting of HSCT, some informative case reports from other settings have also been included. Although it has been stated that measurement of blood CsA concentrations may have limited value in management of an acute CsA overdose [27], quantification of 'on the spot' CsA concentrations, instead of routine scheduled monitoring, would be very informative for discovering the extent of the overdose and decision making about the best therapeutic approach. The 'golden hour' for gastrointestinal decontamination-especially for induction of emesis or lavage and suction-is short, but currently no guideline for the best timing is available. Similar uncertainty exists for implementation of the second step, including more invasive approaches such as WBE. Use of enzyme inducers suffers from lack of adequate experience, unproven efficacy and an increased risk of unexpected peri-transplantation complications, especially in HSCT patients with complex pharmacokinetic and metabolic features. Also, it should be noted that enzyme induction is a time-consuming process [30], so, in acute cases, it should not hinder or replace implementation of more vital measures. Therefore, its place in treatment protocols should be just as an adjunctive therapy. However, if the patient has specific co-morbidities, such as seizure or infection, administration of phenytoin or rifampin, respectively, could be justified. Considering the pharmacokinetic variability of the HSCT population, 'toxicokinetic' studies on early-detected accidental overdose cases in this population would be very enlightening for development of practice guidelines. In comparison with the mean values of the pharmacokinetic parameters that have been calculated for this centre's patients [unpublished data], for our intoxicated patient, clearance of the drug was (fortunately) faster, the half-life was shorter, and the bioavailability was about half the estimated mean value, with similar products. This may, to some extent, explain the short duration and mild presentation of our patient's symptoms. On the other hand, these could have been related to the occurrence of high-grade GVHD in the outpatient setting when our patient was receiving oral CsA dosing. In this patient's toxic state, the drug's half-life was over $12 \mathrm{~h}$, whereas the drug's half-life in a normal situation is $3.85 \mathrm{~h}$. This finding may imply that CsA pharmacokinetics are altered in overdose states.

Besides goal-directed therapies for intoxication-which generally has shown controversial results-supportive care for maintaining organ function or for reversal of dysfunction, such as administration of antioxidants, respiratory support and dialysis, can have a major role in survival of overdosed patients. This fact underscores the importance of frequent monitoring of biomedical and biochemical markers, as was done in our case.

CsA is a critical agent used extensively for immunomodulation in the stem cell transplantation setting, and it has a narrow therapeutic index, so constant awareness on the part of health care providers regarding the possibility of medication errors and detection of toxicity symptoms could possibly decrease CsA-related morbidity and mortality in the future.

Acknowledgments The author wishes to acknowledge the assistance of Radan English Edit for the editing of this manuscript, and Dr. M. Tavakoli and Mr. A. Sharifi Sistani for their supportive supervision.

\section{Compliance with Ethical Standards}

Funding No sources of funding were used in the preparation of this report.

Conflict of interest Ali Tafazoli has no conflicts of interest that are directly relevant to the content of this report.

Ethical approval Written informed consent was obtained from the patient, with a promise for anonymous data publication for the purpose of improvement of clinical care for transplant patients. All activities related to this manuscript were conducted in accordance with the Shahid Beheshti University of Medical Sciences ethical regulations.

Open Access This article is distributed under the terms of the Creative Commons Attribution-NonCommercial 4.0 International License (http://creativecommons.org/licenses/by-nc/4.0/), which permits any noncommercial use, distribution, and reproduction in any medium, provided you give appropriate credit to the original author(s) and the source, provide a link to the Creative Commons license, and indicate if changes were made.

\section{References}

1. Tafazoli A. Cyclosporine use in hematopoietic stem cell transplantation: pharmacokinetic approach. Immunotherapy. 2015;7(7):811-36.

2. Dijkmans B, van Rijthoven A, Goei Thè H, Boers M, Cats A. Cyclosporine in rheumatoid arthritis. Semin Arthritis Rheum. 1992;22(1):30-6.

3. Baumhefner RW, Myers LW, Ellison GW, Tourtellote WW, Belendiuk GW, Wilkinson A, et al. Huge cyclosporin overdose with favourable outcome. Lancet. 1987;2(8554):332.

4. Eagle D, Gian V, Lauwers G, Manivel J, Moreb J, Mastin S, et al. Gastroparesis following bone marrow transplantation. Bone Marrow Transplant. 2001;28(1):59-62.

5. Piñana J, Valcárcel D, Martino R, Barba P, Moreno E, Sureda A, et al. Study of kidney function impairment after reduced-intensity conditioning allogeneic hematopoietic stem cell transplantation: a single-center experience. Biol Blood Marrow Transplant. 2009;15(1):21-9. 
6. Dussol B, Reynaud-Gaubert M, Saingra Y, Daniel L, Berland Y. Acute tubular necrosis induced by high level of cyclosporine A in a lung transplant. Transplantation. 2000;70(8):1234-6.

7. Banner N, Yacoub M. Cyclosporine in thoracic organ transplantation. Transplant Proc. 2004;36(2 Suppl):302S-8S

8. Zager R, O'Quigley J, Zager B, Alpers C, Shulman H, Gamelin $\mathrm{L}$, et al. Acute renal failure following bone marrow transplantation: a retrospective study of 272 patients. Am J Kidney Dis. 1989;13(3):210-6.

9. Trull A, Hue K, Tan K, Gore S, Whitewood S, Smyth R, et al. Cross-correlation of cyclosporine concentrations and biochemical measures of kidney and liver function in heart and heart-lung transplant recipients. Clin Chem. 1990;36(8 Pt 1):1474-8.

10. Nghiem DD. Role of pharmacologic enhancement of p-450 in cyclosporine overdose. Transplantation. 2002;74(9):1355-6.

11. de Perrot M, Spiliopoulos A, Cottini S, Nicod L, Ricou B. Massive cerebral edema after IV cyclosporin overdose. Transplantation. 2000;70(8):1259-60.

12. Shbarou R, Chao N, Morgenlander J. Cyclosporin A-related cerebral vasculopathy. Bone Marrow Transplant. 2000;26(7):801-4.

13. Torelli G, Natalino F, Barberi W, Iori A, Andreoli C, Valle V, et al. Early onset of posterior reversible encephalopathy syndrome (PRES) during cyclosporine A infusion. Leuk Res. 2011;35(10):1423-4.

14. Eisenberg S. The case of the toxic transplant tremors. ONS Connect. 2013;28(3):41

15. Barbui T, Rambaldi A, Parenzan L, Zucchelli M, Perico N, Remuzzi G. Neurological symptoms and coma associated with doxorubicin administration during chronic cyclosporin therapy. Lancet. 1992;339(8806):1421.

16. Taler S, Textor S, Canzanello V, Schwartz L. Cyclosporin-induced hypertension: incidence, pathogenesis and management. Drug Saf. 1999;20(5):437-49.

17. Fujisaki G, Kami M, Murashige N, Kishi Y, Inokuchi C, Tanosaki R, et al. Sinus bradycardia associated with cyclosporine following allogeneic hematopoietic stem cell transplantation. Bone Marrow Transplant. 2005;35(2):211-2.

18. Kingma I, Harmsen E, ter Keurs H, Benediktsson H, Paul L. Cyclosporine-associated reduction in systolic myocardial function in the rat. Int J Cardiol. 1991;31(1):15-22.
19. LoVecchio FA, Goltz HR. Atrial fibrillation following acute overdose with oral cyclosporine. Ann Pharmacother. 2000;34(3): 405.

20. van Hooff J, Bessems P, Beuman G, Leunissen K. The absence of an allergic reaction to cyclosporine capsules in a patient allergic to standard oral and intravenous solutions of cyclosporine. Transplant Proc. 1988;20(2 Suppl 2):640.

21. Honcharik N, Anthone S. Activated charcoal in acute cyclosporin overdose. Lancet. 1985;1(8436):1051.

22. Anderson AB, Primack W. Treatment of a child with acute cyclosporine overdose. Pediatr Nephrol (Berlin, Germany). 1992;6(2):222.

23. Lucey MR, Kolars JC, Merion RM, Campbell DA, Aldrich M, Watkins PB. Cyclosporin toxicity at therapeutic blood levels and cytochrome P-450 IIIA. Lancet. 1990;335(8680):11-5.

24. Leitner GC, Hiesmayr M, Hoecker P, Jilma B. Therapeutic approaches in the management of oral cyclosporine A intoxication. Transplantation. 2003;75(10):1764-5.

25. Kwon SU, Lim SH, Rhee I, Kim SW, Kim JK, Kim DW, et al. Successful whole blood exchange by apheresis in a patient with acute cyclosporine intoxication without long-term sequelae. J Heart Lung Transplant. 2006;25(4):483-5.

26. Moorman M, Epstein R, Smith J, O’Neal C, Holter J. Management of cyclosporine overdose in a hematopoietic stem cell transplant patient with sequential plasma exchange and red blood cell exchange. J Clin Apher. 2011;26(3):156-8.

27. Arellano F, Monka C, Krupp PF. Acute cyclosporin overdose: a review of present clinical experience. Drug Saf. 1991;6(4): 266-76.

28. Ceschi A, Rauber-Luthy C, Kupferschmidt H, Banner NR, Ansari $\mathrm{M}$, Krahenbuhl S, et al. Acute calcineurin inhibitor overdose: analysis of cases reported to a national poison center between 1995 and 2011. Am J Transplant. 2013;13(3):786-95.

29. Fahimi F, Baniasadi S, Najafi Zadeh K. Dose switch to another dosage form of Neoral increase the risk of medication error? Ann Transplant. 2009;14(4):58-60.

30. von Bahr C, Steiner E, Koike Y, Gabrielsson J. Time course of enzyme induction in humans: effect of pentobarbital on nortriptyline metabolism. Clin Pharmacol Ther. 1998;64(1):18-26. 